Article

\title{
The Impact of Mobile Money on the Financial Performance of the SMEs in Douala, Cameroon
}

\author{
Frank Sylvio Gahapa Talom and Robertson Khan Tengeh *iD \\ Department of Entrepreneurship and Business Management, Faculty of Business and Management Sciences, \\ Cape Peninsula University of Technology, Cape Town 7535, South Africa; 212021850@mycput.ac.za \\ * Correspondence: tengehr@cput.ac.za; Tel.: +27-21-460-3450; Fax: +27-86-778-0394
}

Received: 25 November 2019; Accepted: 22 December 2019; Published: 24 December 2019

\begin{abstract}
Often financially excluded by the traditional banking system, small and medium-sized enterprises (SMEs) in many developing countries have found in mobile money services (MMS) a sustainable alternative. Despite its potential in propelling inclusive growth, the use and adoption of mobile money (MM) by SMEs has generally been low in developing countries, and one of the reasons has been limited data that supported its impact on financial performance. As a result, there was a need to investigate the impact of the mobile money payment and receipt services on the financial performance of the SMEs in Cameroon. This paper implemented a mixed research paradigm with data collected through the administration of a survey questionnaire and from one-on-one in-depth interviews. A sample of 285 SMEs responded to the survey, while 12 owners/managing directors were purposively selected to participate in the personal interviews. Version 25 of the Statistical Package for the Social Sciences (SPSS) software was used to analyse the quantitative data, while the qualitative data was analysed along themes. The results were, after that, triangulated for credibility reasons. The concluding findings indicated that the mobile money payment and receipt services contributed of the order of $73 \%$ of the total variance in the turnover of the SMEs in Douala after they had begun to use the technology. By confirming the positive relationship between the use of mobile money services and the financial performance of businesses, it is hoped that all the relevant stakeholders will see this as a possible solution to the financial challenges that SMEs face in developing economies.
\end{abstract}

Keywords: mobile money; SMEs; financial performance; payments and receipts; Douala, Cameroon

\section{Introduction and Background}

Small and medium-sized enterprises (SMEs) make significant contributions to driving the economies of a great many countries. They play a crucial role in socio-economic development by contributing to the creation of wealth, economic growth and employment [1,2]. A 2016 census of enterprises in Cameroon suggested that approximately $99.8 \%$ of the enterprises in the country are SMEs [3]. Furthermore, it was revealed that SMEs accounted for $72 \%$ of the permanent jobs generated in Cameroon [3]. Although they employ around $72 \%$ of the workforce in Cameroon and contribute approximately $35 \%$ of the GDP [4,5], very few are considered to be structurally and financially stable [6].

The SME sector of Cameroon comprises mainly (around 97\%) sole proprietorship or family businesses [3]. It was further noted that approximately $85 \%$ of the managers of these SMEs were relatively poorly educated. Because of their structure and the managerial profile of their managers, SMEs tend to be highly cash-dependent [7-10]. Consequently, they are usually obliged to transact business with suppliers, to buy or pay for goods by travelling to their offices, which can entail considerable risk of theft or losing money. In the case of SMEs which have bank accounts, apart from the disadvantages of costs which are incurred by high bank charges, documentation and transport, owners are frequently required to queue for lengthy periods before they can obtain access to funds, 
which makes it very difficult to exploit any unexpected opportunities which may arise for which funds are required [11]. Because the owners of many of the businesses are sole traders who operate in a very informal manner and the businesses are often staffed only by their owners and possibly one or two members of their families [12,13], they are often obliged to leave their businesses unattended for several hours in order to conduct transactions in a bank [11]. As a consequence, sales are lost, and their prospects for survival are severely compromised [14,15].

As it has become abundantly evident that to survive and achieve growth, SMEs in Cameroon need to streamline their procedures, reduce operating cost and eliminate unnecessary loss of time, the advent of the phenomenon of mobile money could not have been more fortuitous [16]. The system enables the SMEs to receive payments directly from customers and also to make payments directly to suppliers through mobile telephones [17], without being obliged to leave or close their premises for lengthy periods. Accordingly, it provides a viable means for people or SMEs who do not have access to bank accounts to make financial transactions with ease, have access to funds when they are needed, without incurring additional charges such as transport and opportunity cost, and significantly improve the performance of their businesses as a consequence $[18,19]$.

According to Ngaruiya et al. [10], obstacles are inherent in the operations of SMEs. In the case of Cameroon, SMEs needs concerning financial liquidity and banking services are not sufficiently met by commercial banks for several reasons, including a lack of collateral, inadequate bookkeeping systems, and their often questionable viability in the eyes of financial institutions [20-22]. Besides, SMEs bank accounts are not cost-effective, owing to high bank charges and the transport costs which are incurred by travelling to banks to make transactions [10,23-25]. These unwieldy procedures have contributed to the performance of many SMEs in Cameroon stagnating, with low economic growth being but one of a host of adverse consequences. As SMEs comprise the majority of the businesses in the country and in the light of the disastrous effects which cumbersome banking procedures have on their performance, a strong case could be made for the use of mobile money as a means of enabling SMEs to streamline their operations. The platform will improve the mode of receipts and payments, the debt collection procedures which, in return, will enhance the liquidity and working capital management problems faced by the SMEs [23].

Although mobile money does not provide a panacea for all of the financial problems with which SMEs are faced, the benefits far exceed the disadvantages which are associated with adopting the system. Irrespective of whether the system is used in isolation or conjunction with a bank account, it stands to increase the sales of SMEs and reduce their operating costs, with both factors making positive contributions to improving their financial performance [10].

Although a considerable amount of research has been conducted concerning the effects which mobile money has had upon the performance of SMEs in Africa, particularly in Kenya, the topic has not been examined in Douala, Cameroon. The studies that delved in this area include Ngange and Beng [19] that studied the impact of mobile phone usage in economic development in Molyko. Covering a much bigger area, Ojong [26] looked at informal mobile remittances and socioeconomic factors in the North-West Region. Mwafise and Stapleton [27] examined the influence of social-technical and institutional factors on the effective uptake of mobile money electronic payments. Yet, none of the just-mentioned studies investigated the impact of the mobile money services on the performance of SMEs in Douala.

More so, this paper focused principally on the payment and receipt services. Consequently, this study aims to contribute to the mobile money literature on Cameroon by mainly assessing the impact of the mobile money payment and receipt services on the financial performance of the SMEs in Douala, Cameroon. The paper adopted the mixed research method to record and analyse quantitative and qualitative data. The individual methods were further triangulated to increase the credibility of results. In line with similar studies, such as Ngaruiya et al. [10], Mararo and Ngahu [11], Masocha and Dzomonda [18] and Higgins et al. [23], it is hoped that the findings of this paper will be useful to the relevant stakeholders in Douala, Cameroon. 
The rest of the paper is structured as follows. A review of the literature related to mobile money, SMEs and the possible opportunities and challenges associated with the platform. After that, a discussion around the research design methodology, followed by discussions of findings. Finally, the conclusions, limitations of the study and recommendations were provided to the relevant stakeholders. Because of the boundaries of the study, suggestions for future research directions were pointed out.

\section{Literature Review}

\subsection{Mobile Money and SMEs}

Mobile money (MM) is a service which permits customers to obtain access to financial services employing cellular devices [28], by dialling Unstructured Supplementary Service Data (USSD) codes. USSD is a communications protocol for mobile communication technology which is used to send text between mobile telephones and an application programme in the mobile network, which does not require users to have access to the internet. Although the technological innovation is now available in many developing countries, its use is particularly widespread in countries in which it is difficult for many citizens to open bank accounts and/or access banking services [22,29]. It enables users to store, send and receive money without the transactions entailing the use of bank accounts [30].

Mobile money has disrupted the financial sector and the way of transacting. SMEs can now efficiently conduct financial transactions, anytime, and anywhere, without necessarily having a bank account $[10,24,26,30]$. This innovation can help to reach those who do not have access to banking services and thus improve financial inclusion [22]. Ngange and Beng [19] and Chimaobi and Chizoba [31] demonstrated that mobile commerce facilitates communication between users. The later scholars went further to show that the platform improves the efficiency of the business operations. Additional studies conducted respectively by Ngaruiya et al. [10], Higgins et al. [23] and Mbogo [25] proved that mobile money improves business networking, while Amponsah [21], Chimaobi and Chizoba [31] and Ngaruiya et al. [10] demonstrated that the technological innovation promotes a cashless economy. All these benefits taken concurrently will enhance the productivity, decrease the operating costs and thus improve the performance of the SMEs $[10,18,32,33]$.

In the Economic and Monetary Community of Central Africa (CEMAC) region, which is heavily regulated, mobile money is still at an embryonic stage [29]. Mobile money services providers are bound to work with their partner banks to provide their services [30]. This seems to be common practice in many emerging economies, with some exceptions, like in Ghana, where, since 2015, the mobile network operators (MNOs) can now apply for licenses directly from the Central Bank [21]. Mobile network operators are telecommunication entities that provide services for mobile phone subscribers. Also, the mobile money services which are provided are limited by comparison with those which are available in East and West African countries [10,11,33]. In Cameroon, for instance, mobile money is used mainly to make purchases and send and receive money; saving and loan facilities are not yet provided [34,35].

The study identifies four significant platforms for mobile money services (MMS) in Cameroon, namely, MTN Mobile Money, Orange Mobile Money, Express Union Mobile Money and the recently launched Nexttel Possa. By contrast, there are only two service providers, namely, MTN and Orange Cameroon, also known as mobile network operators, which dominate the Cameroonian mobile money market and together account for 5.4 million registered users [36]. Orange, which has 2.8 million registered users, offers the following services: money deposits, money withdrawals, the sending and receiving of money transfers, a Visa card facility, the purchasing of insurance-related products, the transferring of funds between bank accounts and mobile money accounts, the purchasing of airtime and the payment of bills, university fees, transport tickets and school fees [35]. MTN, which has 2.6 million users, offers a similar range of services, with the exception of the Visa card facility, the purchasing of insurance-related products and the transferring of funds between bank accounts and 
mobile money accounts [34]. According to FinMark Trust [22], the Cameroonian population comprised more than 14 million people who were 15 years of age or older in 2017. Combined with the figure of $12 \%$ citizens who hold bank accounts [29] and the average population growth of $2.7 \%$ in Cameroon between 2014 and 2017 [37], it appears that in the region of 1.7 million people held bank accounts, which amounts to around one-third of the 5.4 million registered users of mobile money during the same period. As mobile money is a relatively new phenomenon in Cameroon, it is highly significant that three times more Cameroonians have opened mobile money accounts than hold bank accounts. Similar findings were obtained in at least eight countries [38].

According to Rubini [39], SMEs are considered to be the backbone of most of the developed and developing countries across the globe. The term "small and medium-sized enterprises" is a broad one, and the specific defining attributes tend to vary among individual countries. The categorisation of enterprises with respect to their size on the basis of the numbers of workers which they employ, their annual turnover or capital assets entails fairly arbitrary assessments, which are often influenced by the prevailing business values of individual countries [10]. To cite an internationally accepted criterion, the Organisation for Economic Cooperation and Development classifies SMEs as businesses which do not employ more than 249 employees [1]. For practical purposes, having the number of employees as a defining criterion provides a useful comparative measure for assessing the sizes of businesses [1]. In Cameroon, the official definition is derived from the law No 2010/001 of 13 April, 2010 for the promotion of small- and medium-sized enterprises [40]. It holds that any company with an annual turnover (excluding tax) which does not exceed FCFA 1 billion and employs a permanent workforce of not more than 100 employees is considered to be an SME [41]. The FCFA is denomination of the common currency of 14 African countries which are members of the Franc Zone. As per their contribution into the economic and the social well-being across the globe [1,39], Cameroonian SMEs play a crucial role in achieving economic growth by contributing up to $72 \%$ of the national workforce [3] and approximately 35\% of the GDP [4]. Despite their important responsibility, the majority in emerging countries face many difficulties, with the most important being that of financing $[3,4,14,42]$. In developing countries such as Ghana, Tanzania and Kenya, credit systems have been developed by MNOs which are based upon transactional histories of mobile money, which make it possible to grant microloans to SMEs [43]. In Cameroon, it is the State that made an effort by opening a bank for the SMEs in July 2015 [44]. However, even if the MNOs cannot offer microcredit in Cameroon, it is perceived by many scholars that the mobile money services facilitate the commercial dealings for SMEs [19,31]. According to Ngaruiya et al. [10] and Amponsah [21], the rapid diffusion of mobile money transfer is seen as a potentially vital tool for facilitating financial transactions. This indicates that the rapid adoption of mobile money Services is seen as a way to improve the financial functionality and hence the performance of the SMEs. For Pinem and Dwi [45], the performance of the SMEs can be measured by evaluating the sales growth, which remains one of the main determinants of SMEs performance [46]. The significance of the MMS seems to be mitigated in a good number of countries due to delays in telecommunication infrastructures [47]. Nevertheless, as demonstrated by Ngaruiya et al. [10], Masocha and Dzomonda [18], Higgins et al. [23], Mbogo [25], Chale and Mbamba [32] and Nyaga and Okonga [33] —in their respective studies, the platform has improved the financial performance of SMEs after they have begun to use it.

\subsection{Opportunities}

Apart from the role which the system has played in increasing rates of financial inclusion, businesses which adopt mobile money services benefit from a wide range of different advantages and opportunities [21]. Among the many other advantages which it provides is the ability to transfer money at a low cost within a branchless bank [10,33]. Evidence from studies carried out in Kenya and Ghana attest to how the use of MM ensures a seamless cash flow, easier and safer financial transaction for SMEs $[10,21]$. The concept of a cashless economy is enthusiastically promoted by many central banks throughout Africa [10,21,31]. Ngaruiya et al. [10] point out that the adoption of the system 
has facilitated decision-making and the exchange of information, improved the ability of businesses to network successfully and increased the competitiveness of SMEs. The findings of a study which was conducted by Chimaobi and Chizoba [31] revealed that SMEs in Nigeria, which traded using mobile systems, were able to shorten their delivery times significantly. Both Ngange and Beng [19] and Chimaobi and Chizoba [31] — maintain that using mobile money services facilitates communication between users and improves relationships between buyers and sellers. Effective communication has also significantly reduced the effects of the phenomenon which is known as asymmetric information or information failure between users, which results from one user in a transaction having significantly more information on it than the other. Increasing the range of opportunities which are available to users via the platform would create added value for SMEs and enable them to reduce their operational expenses and, indirectly, improve their performance and growth $[18,23,25,32,33]$. Despite the immense opportunities which mobile money services provide to users, groups of factors continue to militate against their universal adoption.

\subsection{Difficulties}

The principal categories of factors which tend to discourage the universal adoption of mobile money services are mainly regulatory, infrastructural and those which arise from traditional perceptions [24,39,48-51]. Mobile money remains heavily regulated $[24,39]$. In some instances, stakeholders in the traditional banking sector tend to perceive the new system as a threat to the hegemony which they have maintained [24] and do not welcome the prospect of their services being superseded or supplanted by innovative contemporary ones [21]. The pressure which commercial banks are placing upon the central banks of their countries leave them with two possible courses of action: continue with the status quo and retard economic growth as a consequence of stifling the growth of SME sectors or liberalise and permit newcomers to the financial sectors of their countries to boost national economies by providing services which significantly increase the financial performance of SMEs $[21,24,39,48]$. Limited infrastructure has made it impossible to make mobile money services available to all of the members of the populations of some countries [42,47]. As has already been noted, cellular coverage tends to be low in many developing countries [49]. As it is particularly low in rural areas, many people are effectively denied access to the advantages which cellular technology provides [49]. Unstable networks and interrupted transmission oblige some users of mobile money services to travel to locations in which their networks are functioning normally to make transactions, thereby incurring additional costs and suffering considerable inconvenience [47]. According to Chimaobi and Chizoba [31], the erratic transmissions of energy by the power supplier also affect users of mobile money services adversely. During blackouts, it is impossible to make transactions (mobile signals blackout), and, in some instances, cellular devices are damaged beyond repair (electricity blackout). Significant numbers of members of the populations of developing countries tend not to trust modern technology and prefer to carry cash with them, owing to the degree of control over their transactions which they perceive that doing so provides [47]. For instance, it is not possible to request a refund or to stop a transaction which has already been validated in a mobile money transaction, while it is easy to do so in the case of cash payment in a supermarket. Moreover, in Pakistan, no matter the level of education, people still prefer to keep money at home [51].

\subsection{Mobile Money Evolution in Cameroon}

Mobile money was first launched in Cameroon in 2011. The Cameroonian subsidiaries of telecommunication leaders MTN and Orange pioneered the concept and officially launched it in 2012 [52]. The circumstances which prompted its launching were similar to those of most developing countries, particularly concerning the small numbers of members of the population who held bank accounts [29]. As had been the case in the other countries in which the concept had been launched, many households and SMEs in Cameroon had been effectively excluded from the traditional banking system and without access to funding in the formal sector [3,4,42].

Although the services which mobile money provides in Cameroon do not include financing now, its introduction had significantly increased the financial inclusion rate (29\%) by 2017 [22], from $9 \%$ 
in 2012 [53]. As a direct consequence, many citizens have been able to ply trades and launch startup enterprises, which have resulted in indirect employment for of the order of 5000 people [54]. The mobile money transactions which have accompanied this surge amount to in the region of FCFA 3500 billion in 2017, a figure which represents $17.5 \%$ of the GDP of Cameroon [53]. This represents an increase of more than $1000 \%$ from the FCFA 300 billion recorded in 2016 [53].

The introduction of mobile money has enabled Cameroonian households to incur reduced costs by saving and reduce the risk of loss and theft which had accompanied saving in the past $[21,22,24,48]$. As the mobile telephone penetration rate was $71 \%$ in 2014 [52], and that of holding bank accounts had been one of the lowest in the world at $12 \%$ [29], it is abundantly evident that mobile money could not have arrived in Cameroon at a more promising time. The mobile money service in Cameroon is provided through a partnership between commercial bank and mobile network operators (MTN Cameroon, Orange Cameroon, CAMTEL, and Nexttel) because only commercial banks are allowed to issue electronic money [30], and the mobile network operators own the telecommunication infrastructures and technologies to deploy the platform. This regulating arrangement of convenience is the status currently prevailing in Cameroon and will surely deter the significance of the MM in the long run.

Although its importance is affected by factors related to regulation, infrastructures and customs, Mobile Money appears to be the solution to the multiple problems, namely, liquidity, means of payments, debt collection, working capital and financing faced by SMEs. Its adoption and usage in their day-to-day activities have had a positive impact on their performance, as shown by many scholars.

\section{Research Design and Methodology}

This study opted for the pragmatism paradigm. The positivism and interpretivism philosophies were adopted in order to collect data from SMEs in "Mboppi" and "Central" markets. The researcher elected to make use of both quantitative and qualitative research methods in this study to obtain as complete an understanding as possible of the research problem and to make effective use of any converging information which the quantitative and qualitative studies generated. The strategy also enabled the researcher to perform a rigorous evaluation of the reliability of the findings by using the qualitative findings to corroborate the results which the survey questionnaire generated through triangulation.

\subsection{Sampling Technique}

In this study, the researcher was unable to determine, with an acceptable degree of exactitude, how many of the SMEs which qualified for selection in the two markets were using mobile money services to make and receive payments. Also, the criteria concerning the periods for which the SMEs had been operating and the numbers of employees which they had made it even more difficult to identify and obtain access to potential participants. Using simple random sampling would have entailed an unacceptable degree of difficulty, been excessively time-consuming and entailed expense which the researcher could not afford.

Polit and Beck [55] explain that sampling is a method of choosing a portion of a target population to represent the population as a whole in the respects in which particular researchers are interested in the purposes of their studies. The researcher elected to use nonprobability sampling to select participants who were readily identifiable as fulfilling the criteria for inclusion in the research sample and drew upon their knowledge of local SMEs to locate other potential participants through snowball sampling $[55,56]$.

Mindful that qualitative phase seeks to understand better the underlying reasons and motivations rather than to quantify and generalise to a broader population, it is inappropriate to use random sampling techniques [57]. The participants for the in-depth interviews were purposively selected from among the respondents to the questionnaire based on their sales turnover, to obtain a research sample whose members represented SMEs whose turnover ranged from the minimum to the maximum levels and also adequately served those with intermediary levels of turnover. The survey questionnaire was 
administrated over 12 weeks, between November 2018 and January 2019; while in-depth interviews took around six weeks, from February to March 2019.

\subsection{Sampling Size}

Conscious of many restrictions including time, finance and limited access and the fact that the population as a whole is too large to work with, the researcher was not able to collect or analyse data from the entire population. As Dudovskiy [58] maintains that a sample size of twelve is sufficiently large for a qualitative study of a homogeneous population, the researcher selected to conduct twelve in-depth interviews.

For the quantitative component, the researcher encountered a considerable amount of difficulty in determining an optimal sample size for the administration of the survey questionnaire, in the absence of official statistics concerning the numbers of the SMEs which were making use of mobile money services in the two markets, and even more difficulty in identifying SMEs which had been operating for two years or more. Consequently, the researcher elected to use the formula which Cochran [59] developed to calculate the size of the research sample for the quantitative study: $n_{0}=\frac{Z^{2} p q}{e^{2}}$, where $n_{0}$ is the sample size, $Z^{2}$ is the abcissa of the normal curve that cuts off an area $\alpha$ at the tails (1- $\alpha$ equals the desired confidence level, e.g., $95 \%$ ), e is the margin of error, $p$ is the projected percentage of a characteristic which is to be found in a population and $q$ is $1-p$. The value of $Z$ is found in the statistical tables which contain the area under the normal curve [60].

Following the application and the computation of the Cochran's formula [59] at a confidence level of $95 \%$, a margin error of $5 \%$ and a standard deviation of $50 \%$, the researcher obtained a sample size of 384 for the quantitative phase of the study. The sample size of 384 was considerably greater than those who had been used in similar studies which have been conducted in countries in which the use of mobile money services is widespread. The researcher calculated an average sample size of 228 by consulting the literature pertaining to the studies which had been conducted by Ngaruiya et al. [10], Mararo and Ngahu [11], Higgins et al. [23] and Nyaga and Okonga [33]. After having given due consideration to the relatively new status of the mobile money industry in Cameroon, the relatively limited adoption of money market services in Cameroon by comparison with Kenya, the relatively short lifespans of many SMEs in Cameroon [6] and the constraints which time and financial considerations imposed, the researcher decided upon a sample size of 250 for the quantitative study. To compensate for any unusable questionnaires and to ensure that the final sample size was as close to 250 as possible, the researcher distributed a total of 300 questionnaires evenly among potential respondents in both markets. After he had collected and sorted the completed questionnaires, it emerged that 285 were usable, of which 142 had been completed by respondents in the Central Market and the remaining 143 by respondents in the Mboppi market. As the 285 completed questionnaires significantly exceeded the initial target figure of 250 , it was likely that the credibility of the findings would be substantially increased.

\subsection{Measures Taken to Ensure the Credibility of the Findings}

Although it is not possible to eliminate the possibility of the findings of research studies lacking credibility, researchers need to take all reasonable measures to do so [58]. Credibility refers to the extent to which accounts which are provided by researchers are plausible and appropriate, particularly concerning the degree to which their findings accord with the perceptions of the participants in their studies [55]. Credibility is predicated upon the criteria of reliability and validity to evaluate the quality of research.

\subsubsection{Reliability}

According to Dudovskiy [58] and Asoba [61], reliability refers to the consistency with which particular research instruments generate data. Consequently, the reliability of the findings of a study is assessed in accordance with the likelihood that other researchers would be able to generate similar 
findings under the same conditions and using the same research techniques. As such, the reliability of the findings of this paper was ensured by pilot testing both the survey questionnaire and the interview guide and by subsequently corroborating the findings of the quantitative study with those which were obtained from the face-to-face in-depth interviews.

\subsubsection{Validity}

According to Polit and Beck [55], validity can be defined as the degree to which a research instrument measures what it is intended to measure. From a slightly different standpoint, Dudovskiy [58] evaluates the validity of findings as a measure of the degree to which the requirements of a particular scientific research methodology have been adhered to during the process of generating research findings. In both instances, it is evident that validity is a measure of accuracy. Creswell [62] explains that in mixed methods research, the findings from quantitative studies are used to validate those of qualitative studies and vice versa. As this study employed a mixed methods research design, the findings from the administration of the survey questionnaire were validated against those which the in-depth interviews generated.

\section{Findings and Discussions}

\subsection{Results of the Quantitative Phase}

4.1.1. Monthly Levels of Turnover in FCFA Before and After the Adoption of Mobile Money Services

Figure 1 depicts the levels of monthly turnover, which the respondents claimed on behalf of their SMEs before and after they had elected to make use of mobile money services. The ranges into which their respective levels of turnover fell are summarised in Table 1 . The results in Table 1 denote that the average turnover of the SMEs in Douala increased by 0.44 , almost $12 \%$, after they have begun using mobile money services. It can be seen in Figure 1 that before they elected to make use of mobile money services, 69 out of 285 SMEs had achieved monthly turnovers of from FCFA 200,001 to FCFA 500,000, the figures rose to 75 after they had done so. Also, the numbers of SMEs which achieved monthly turnovers of more than FCFA 1 million rose from forty, before the adoption of mobile money, to sixty, after having done so, which represents an increase of 50\%. The findings of a study which was conducted by Ngaruiya et al. [10] in Kenya were essentially similar to those of this study in these respects.

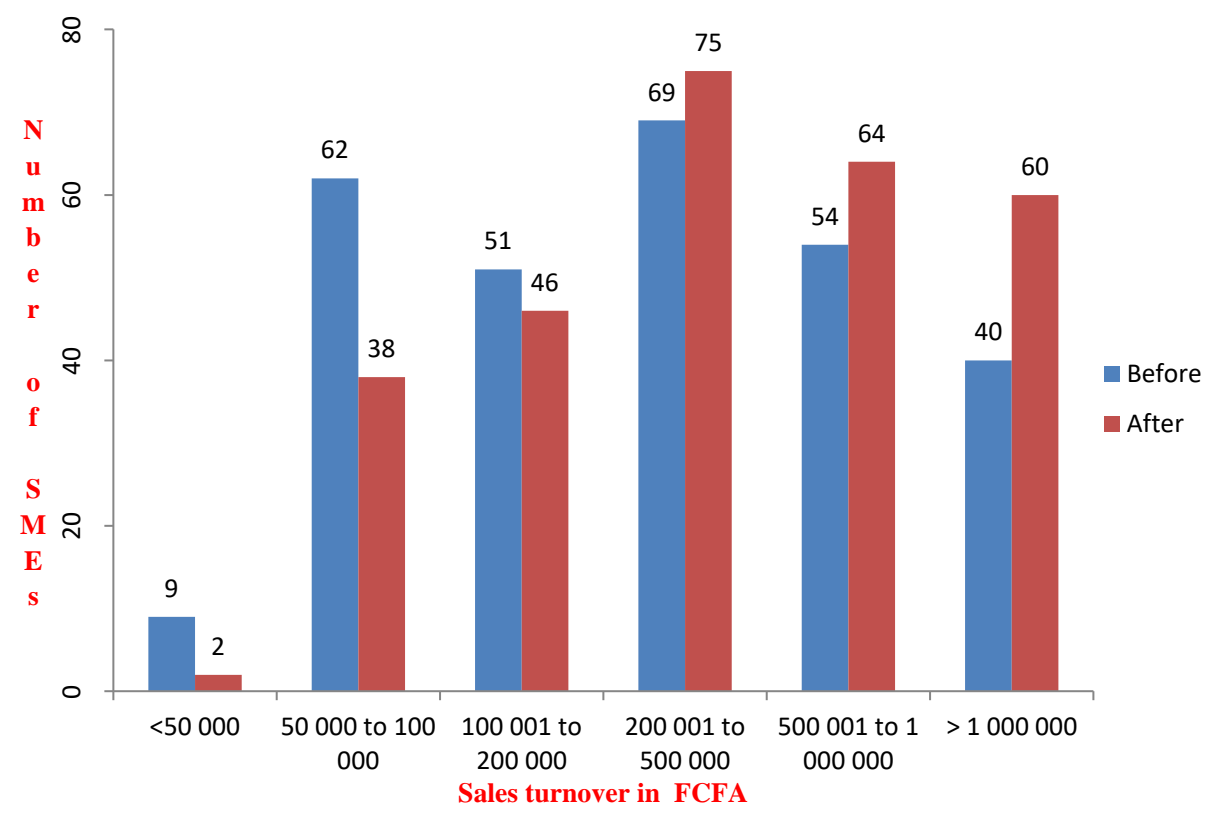

Figure 1. Monthly turnover figures in FCFA before and after the adoption of mobile money services (MMS) (Source: authors). 
Table 1. Average levels of monthly turnover before and after the adoption of MMS.

\begin{tabular}{cccc}
\hline & $\begin{array}{c}\text { Monthly Turnover in FCFA } \\
\text { before the Adoption of } \\
\text { Mobile Money Services }\end{array}$ & $\begin{array}{c}\text { Monthly Turnover in FCFA } \\
\text { after the Adoption of Mobile } \\
\text { Money Services }\end{array}$ \\
\hline \multirow{2}{*}{$\mathrm{N} \quad$} & 285 & 285 \\
\cline { 2 - 4 } & Valid & 0 & 0 \\
\hline \multicolumn{2}{c}{ Missing } & 3.76 & 4.20 \\
\hline \multicolumn{3}{c}{ Sean } & \multicolumn{3}{c}{}
\end{tabular}

\subsubsection{Perceptions of the Respondents of Mobile Money and Mobile Money Services}

Figure 2 depicts the distributions of the responses of the respondents according to a 5-point Likert scale concerning their perceptions of mobile money and mobile money services. A significant majority $(67 \%)$ of the respondents either agreed or strongly agreed that it was affordable and straightforward to register a mobile money account. A similar majority (65\%) either agreed or strongly agreed that mobile money transactions were safe, while (54\%) either agreed or strongly agreed that mobile money service providers were reliable. By contrast, the majority (130) either disagreed or strongly disagreed that using mobile money services to make and receive payments had significantly influenced the turnover of their businesses, while ninety-two respondents chose to record neutral responses, by comparison with a total of sixty-three who either agreed or strongly agreed with the statement. The perceptions of the respondents were significantly skewed towards either negative or neutral responses to the statement that their sales had increased after they had begun to make and receive payments by means of mobile money, as they accounted for 196 of 285 responses. The spread of responses to the statement that the adoption of mobile money services to make and receive payments had improved their cash flow was similar, although an even larger group of 107 recorded neutral responses. There was a significant consensus of 242 respondents who either agreed or strongly agreed that mobile money payments and receipts reduced transport costs, while 198 either agreed or strongly agreed that they reduced the cost of transactions. A further 133 either agreed or strongly agreed that they reduced opportunity costs, while 184 either agreed or strongly agreed that they were more cost-effective than the services of banks.

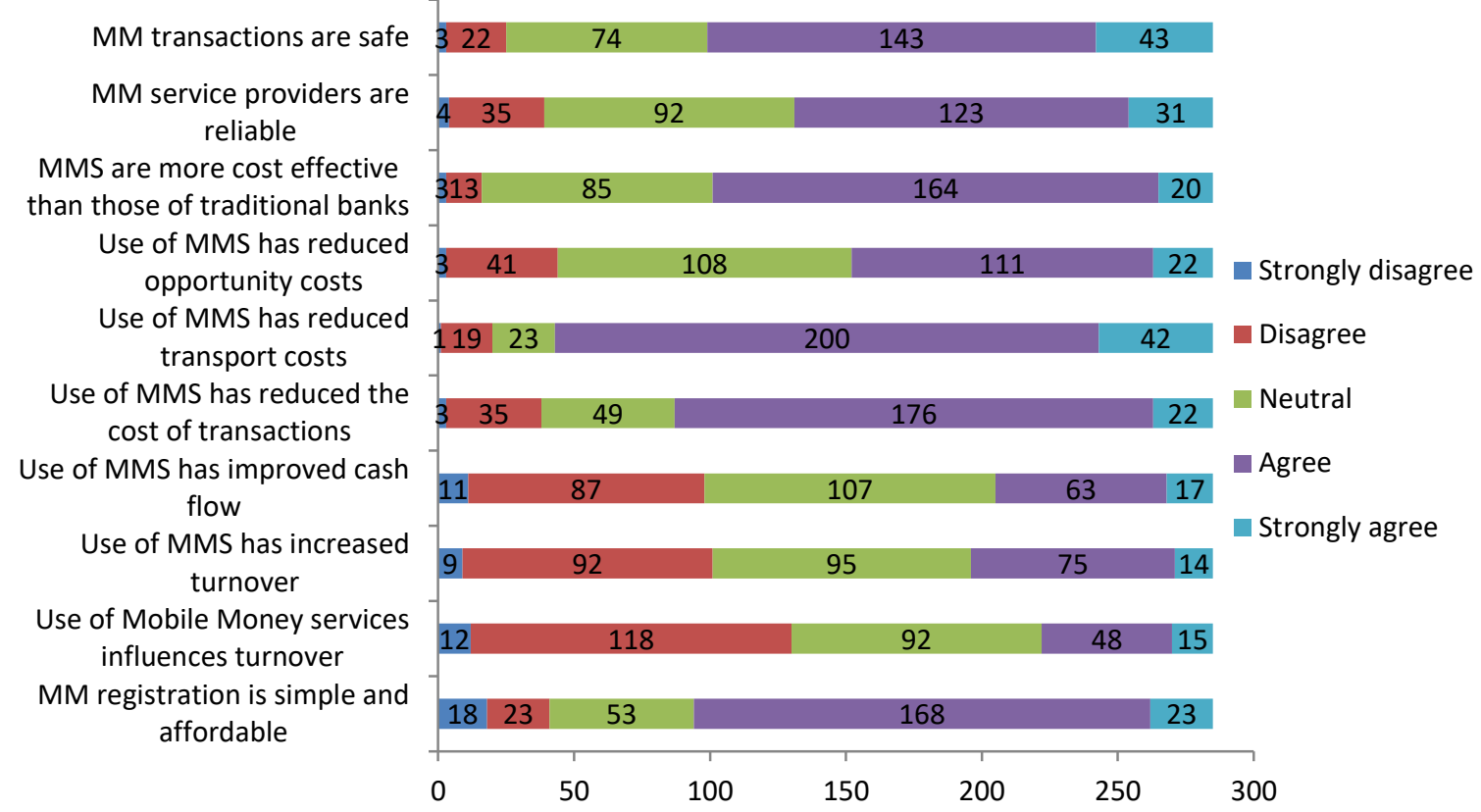

Figure 2. Perceptions of the respondents of Mobile Money (MM) and Mobile Money services (Source: authors). 
4.1.3. Evaluation of the Perceived Impact of Mobile Money Payments and Receipts on the Financial Performance of SMEs in Douala

The researcher identified nine variables from the data to form a reliable scale against which to assess the influence of Mobile Money and Mobile Money services upon the financial performance of the SMEs whose representatives responded to the survey questionnaire. The researcher evaluated their reliability by using the SPSS version 25 software to determine a Cronbach alpha score for each before commencing with the analysis to test the hypotheses in the study. The nine variables, along with their respective Cronbach alpha scores, are summarised in Appendix A, Table A1. As Goforth [63] explains, Cronbach's alpha $\alpha$ scores need to be at least from 0.65 to 0.8 if they are to denote significance. The alpha coefficient noted in Table 2 is 0.659 , which suggests that the items exhibit a reasonable degree of internal consistency concerning reliability. Reliability refers to the consistency with which particular research instruments generate data and is assessed by the likelihood that other researchers would be able to generate similar findings under the same conditions and using the same research techniques [58,61].

Table 2. Reliability analysis.

\begin{tabular}{ccc}
\hline Cronbach's Alpha & $\begin{array}{c}\text { Cronbach's Alpha Based } \\
\text { on Standardized Items }\end{array}$ & No. of Items \\
\hline 0.659 & 0.646 & 9 \\
\hline \multicolumn{3}{c}{ Source: authors. }
\end{tabular}

After that, Pearson's correlation analysis was conducted. For the purposes of performing the analysis, the variables have been recoded as follows: YE for years for which the SMEs of the respondents had been in existence, BA for does your business hold a bank account? AY for number of years since the adoption of MMS, MMSCETB for MMS are more cost effective than the services of traditional banks, MMSIT for using Mobile Money services influences turnover, TBA for monthly turnover before the adoption of MMS, TAA for monthly turnover after the adoption of MMS, NOPDS for number of Mobile Money payments per day to suppliers, EDU for levels of educational attainment and BS for business sectors in which the SMEs of the respondents operated. As can be seen in Table 3, the values of the correlation coefficient $(r)$ for correlations between the variables which were regressed ranged from 0.149 to 0.834 . The values reveal that there were correlations between all variables and turnover, with the exceptions of BA, EDU, and BS. It can be drawn from Table 2 that there was a significant and robust correlation at the 1 percent level between monthly turnover before the adoption of Mobile Money services and afterwards. Although there were correlations with all of the other significant variables, they were relatively weak. It was meaningful to note that the strong positive relationship between the variables TBA and MMSCETB — which was reflected in the value of 0.191 at the 1 percent level, dropped sharply after the adoption of Mobile Money services. This finding suggests that although many of the respondents may have believed before they started to use Mobile Money to make and receive payments that the availability of a more cost-effective system would increase their turnover, their perceptions changed after they started to use the system. It is also significant that the strength of correlations increased after the adoption of Mobile Money services for the variables YE, MMSIT and NOPDS. It is possible to infer from them that as the turnover of the SMEs increased over time, their increasing numbers of payments to suppliers per day also increased their turnover, thereby contributing to perceptions of Mobile Money transactions increasing turnover. This scenario also emerged from the findings of earlier studies which were conducted by researchers such as Ngaruiya et al. [10], Higgins et al. [23] and Nyaga and Okonga [33] -. Once the correlations had been determined between the independent and dependent variables, the researcher elected to investigate the proportion of variance in the dependent variable accounted for by the independent variables using the regression analysis. The R-square value of 0.733 in the model summary in Table 4 suggests that taken together, the independent variables explained of the order of 73 percent of the total variance in the turnover of SMEs in Douala after the adoption of Mobile Money services. From this 
finding, it would appear that the independent variables which have been cited collectively constitute a credible predictor of financial performance for SMEs in Douala.

Table 3. Correlation analysis.

\begin{tabular}{|c|c|c|c|c|c|c|c|c|c|c|c|}
\hline & & YE & BA & AY & $\begin{array}{l}\text { MMS } \\
\text { CETB }\end{array}$ & MMSIT & TBA & TAA & NOPDS & EDU & BS \\
\hline BA & & 0.023 & 1 & -0.080 & 0.055 & -0.095 & -0.039 & -0.108 & $-0.154^{* *}$ & -0.052 & 0.066 \\
\hline AY & & $0.237 * *$ & -0.080 & 1 & 0.001 & -0.012 & $0.189^{* *}$ & $0.143 *$ & $0.243 * *$ & $-0.141 *$ & -0.011 \\
\hline MMSIT & Pearson & $-0.130 *$ & -0.095 & -0.012 & 0.059 & 1 & 0.232 ** & $0.285^{* *}$ & 0.053 & 0.083 & 0.075 \\
\hline TBA & Correlation & $0.149 *$ & -0.039 & $0.189 * *$ & $0.191 * *$ & $0.232 * *$ & 1 & $0.834^{* *}$ & $0.179 * *$ & 0.100 & 0.048 \\
\hline TAA & & $0.173 * *$ & -0.108 & $0.143 *$ & 0.064 & $0.285^{* *}$ & $0.834^{* *}$ & 1 & $0.266^{* *}$ & 0.113 & 0.040 \\
\hline BS & & -0.133 * & 0.066 & -0.011 & 0.047 & 0.075 & 0.048 & 0.040 & 0.061 & 0.165 ** & 1 \\
\hline
\end{tabular}

**. Correlation is significant at the 0.01 level (two-tailed). * Correlation is significant at the 0.05 level (two-tailed). Years in existence (YE), Does your business hold a bank account? (BA), Years since adoption of MMS (AY), MMS more cost-effective than services of traditional banks (MMSCETB), MMS influences turnover (MMSIT), Monthly turnover in FCFA before adoption of MMS (TBA), Monthly turnover in FCFA after adoption of MMS (TAA), Number of payments per day using Mobile Money (NOPDS), Levels of educational attainment (EDU), Business sectors in which the SMEs of the respondents operated (BS). Source: authors.

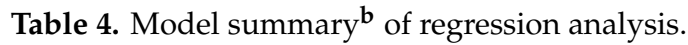

\begin{tabular}{ccccccccccc}
\hline \multirow{2}{*}{ Model } & \multirow{2}{*}{$\mathbf{R}$} & \multirow{2}{*}{ R Square } & $\begin{array}{c}\text { Adjusted } \\
\text { R Square }\end{array}$ & \multirow{2}{*}{$\begin{array}{c}\text { Std. Error of } \\
\text { the Estimate }\end{array}$} & \multicolumn{5}{c}{ Change Statistics } \\
\cline { 6 - 10 } & & & R Square Change & F Change & df1 & df2 & Sig. F Change & Durbin-Watson \\
\hline 1 & $0.856^{\mathrm{a}}$ & 0.733 & 0.727 & 0.699 & 0.733 & 127.113 & 6 & 278 & 0.000 \\
\hline
\end{tabular}

${ }^{\text {a }}$ Predictors: (Constant), Number of payments per day using Mobile Money (NOPDS), Years in existence (YE), MMS influences turnover (MMSIT), MMS more cost-effective than services of traditional banks (MMSCETB), Years since adoption of MMS (AY), Monthly turnover in FCFA before adoption of MMS (TBA). b. Dependent Variable: Monthly turnover in FCFA after the adoption of MMS (TAA). Source: authors.

From the regression findings which appear in Table 5 and after substitution of coefficients $(\beta \ldots)$ and variables $(Y$ and $X \ldots)$ onto the generic regression equation $(Y=\beta 0+\beta 1 X 1+\beta 2 X 2+\beta 3 X 3+\beta 4 X 4$ $+\beta 5 X 5+\beta 6 X 6)$, the researcher obtained the following function:

$$
Y=1.098+0.108 X 1-0.123 X 2-0.154 X 3+0.152 X 4+0.752 X 5+0.243 X 6
$$

where $\mathrm{Y}$ is the dependent variable (turnover after adoption of Mobile Money), $\mathrm{X} 1$ the independent variable 1 (years of existence), X2 the independent variable 2 (years since adoption of MMS), X3 the independent variable 3 (Mobile Money services are more cost-effective than services of traditional banks), X4 the independent variable 4 (MMS influence turnover), X5 the independent variable 5 (monthly turnover before adoption of Mobile Money) and X6 the independent variable 6 (number of payments to suppliers per day using Mobile Money).

Table 5. Regression coefficients ${ }^{\text {a }}$ table.

\begin{tabular}{|c|c|c|c|c|c|c|c|c|}
\hline \multirow[t]{2}{*}{ Model } & \multicolumn{2}{|c|}{$\begin{array}{l}\text { Unstandardised } \\
\text { Coefficients }\end{array}$} & \multirow{2}{*}{$\begin{array}{c}\begin{array}{c}\text { Standardised } \\
\text { Coefficients }\end{array} \\
\text { Beta }\end{array}$} & \multirow[t]{2}{*}{$\mathbf{t}$} & \multirow[t]{2}{*}{ Sig. } & \multicolumn{3}{|c|}{ Correlations } \\
\hline & B & Std. Error & & & & Zero-order & Partial & Part \\
\hline (Constant) & 1.098 & 0.320 & & 3.427 & 0.001 & & & \\
\hline Years of existence & 0.108 & 0.041 & 0.086 & 2.638 & 0.009 & 0.173 & 0.156 & 0.082 \\
\hline Years since the adoption of MMS & -0.123 & 0.072 & -0.057 & -1.702 & 0.090 & 0.143 & -0.102 & -0.053 \\
\hline $\begin{array}{l}\text { MMS more cost-effective than } \\
\text { services of traditional banks }\end{array}$ & -0.154 & 0.059 & -0.083 & -2.598 & 0.010 & 0.064 & -0.154 & -0.081 \\
\hline MMS influence turnover & 0.152 & 0.045 & 0.108 & 3.345 & 0.001 & 0.285 & 0.197 & 0.104 \\
\hline $\begin{array}{l}\text { Monthly turnover in FCFA before } \\
\text { adoption of MMS }\end{array}$ & 0.752 & 0.032 & 0.801 & 23.639 & 0.000 & 0.834 & 0.817 & 0.733 \\
\hline $\begin{array}{l}\text { Number of Payments per day using } \\
\text { Mobile Money }\end{array}$ & 0.243 & 0.066 & 0.121 & 3.676 & 0.000 & 0.266 & 0.215 & 0.114 \\
\hline
\end{tabular}

${ }^{\text {a }}$ Dependent variable: monthly turnover in FCFA after the adoption of MMS (TAA). Source: authors.

The findings which are summarised in Table 5 confirm those which appear in Table 3, in that all of the independent variables apart from MMSCETB correlate positively with the turnover after 
the adoption of Mobile Money. All of the independent variables, apart from years since adoption, are significant at the 5 percent level. It needs to be emphasised that the findings suggest that a unit increase in the monthly turnover of SMEs in Douala before the adoption of Mobile Money to make and receive payments should result in a 75 percent increase in their financial performance after the adoption of the system, ceteris paribus. They also reveal that unit increases in the numbers of payments to suppliers per day and the perception that Mobile Money services are more cost-effective than those of traditional banks result in an increased coefficient value of 0.243 and a decreased one of -0.154 , respectively, for the independent variables if the coefficients for other variables are kept constant.

\subsection{Results of the Qualitative Phase}

Has the adoption of Mobile Money Services to make and receive payments improved your business operations?

The question of whether the adoption of Mobile Money to make and receive payments had improved the operations of the interviewees drew mixed responses as shown in Figure 3, with 58 percent perceiving an improvement while the remaining 42 percent did not. In the words of interviewee A:

"There is no change. I am still making more or less around the same turnover. The only advantage I may acknowledge is that it makes it unnecessary for me to leave my business premises."

This response confirmed that convenience was a motivating factor for the adoption of Mobile Money to make and receive payments. As interviewee D explained,

"The majority of my customers use Mobile Money services, especially those outside of Douala. Mobile Money services have improved my operation and made it very fluid. Now, people can pay for goods from wherever they are in Cameroon and receive them."

It needs to be emphasised that improved business operations are likely to result in increased sales turnover, a definitive indicator of both growth and financial performance. The overall finding displayed in Figure 3 was that the acknowledgement of seven of the twelve interviewees that the adoption of Mobile Money for payments and receipts had improved their business operations represented an acknowledgement that doing so had improved the financial performance of their businesses.

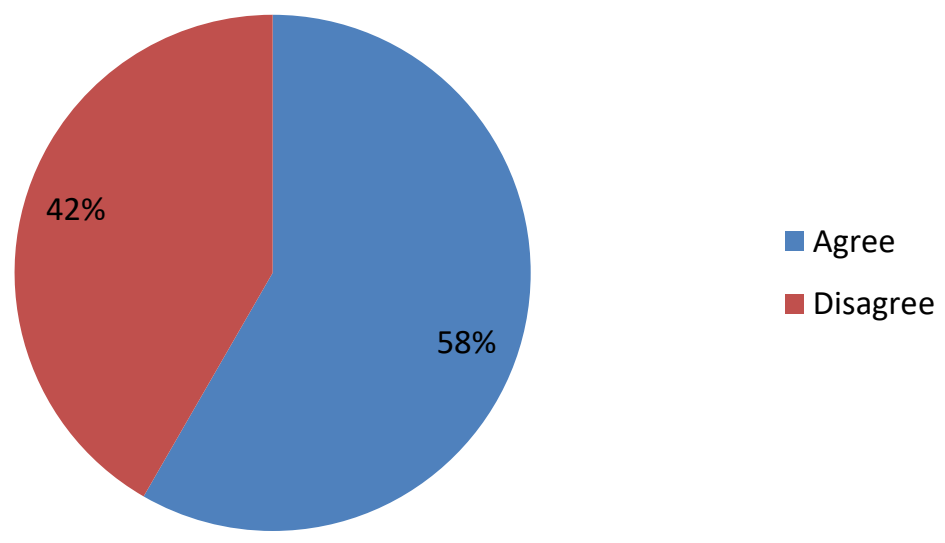

Figure 3. Perceived impact of the Mobile Money Services on the business operations (Source: authors).

\subsection{Triangulation of Results from Both Phases}

The triangulation process helps to confirm the interpretations which researchers have made of their data $[62,64]$. The findings which were obtained from the personal interviews in the qualitative study were used to validate those which emerged from the administration of the survey questionnaire in the quantitative study. Figure 4 is a schematic representation of the procedures which the researcher followed to triangulate the main findings from both phases. From the results, it can be concluded that the mobile money payment and receipt services have impacted on the financial performance of the SMEs in Douala, Cameroon after they had begun to use the platform. 


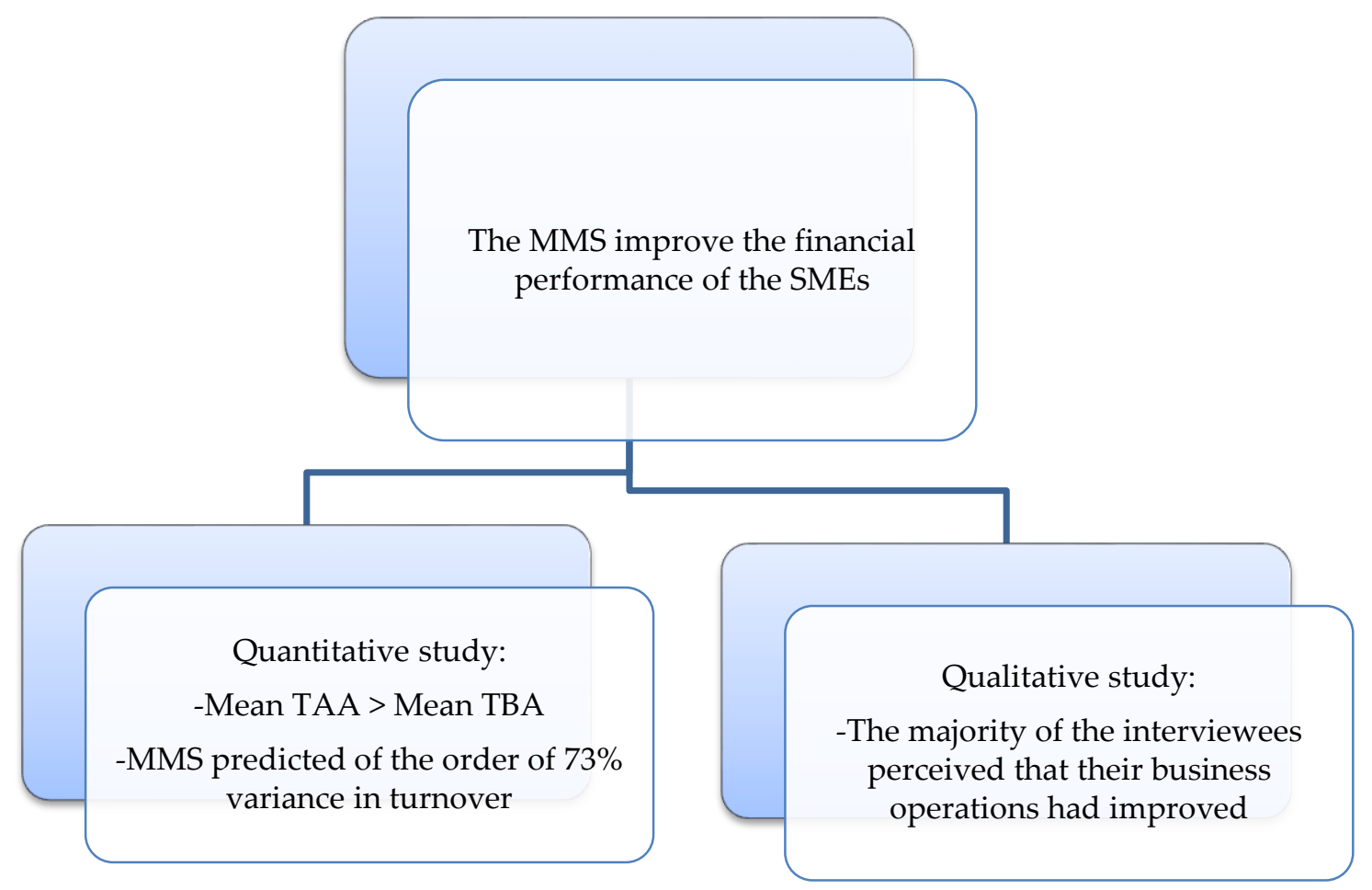

Figure 4. Triangulation of findings (SMEs: small and medium-sized enterprises. Source: authors).

\section{Conclusions and Recommendations}

Over the past decade, Mobile Money has improved financial inclusion in several developing countries but has also improved the way of life of many households and the business operations of many SMEs. The Mobile Money services merits could be used to address some of the difficulties faced by the SMEs in Douala, Cameroon. Mindful of these advantages and the growing uptake of the platform in Douala, the researchers investigated the impact of the mobile money payment and receipt services on financial performance. Taken collectively, the independent variables predicted $73 \%$ of the variance in sale turnover of the SMEs that participated in the study after they had begun to use Mobile Money services. In line with the literature, it can be concluded that the adoption of Mobile Money services exerted a significantly positive influence on the financial performance of the SMEs in this study. A finding which could plausibly be generalised at least to the two markets in Douala in Cameroon in which the study was conducted.

Considering the principal sources of difficulty which the participants identified with respect to the effective running of their businesses, and the perceived role of SMEs in economic growth, one would recommend firstly that the SMEs in Douala should make full use of Mobile Money services given its potential to improve financial performance. Secondly, that the government should investigate the feasibility of promulgating laws that would make Mobile Money service providers licensed financial institutions, as this would significantly reduce their operating costs and enable them to make their services more accessible to users. The partnerships which Mobile Money service providers have with commercial banks at present entail considerable expense and prevent them from making their services more affordable. Thirdly, the paper recommends that the government should encourage SMEs to make Mobile Money transactions through appropriate tax incentives. Finally, the government, through the Ministry of Small and Medium-sized Enterprises, Social Economy, and Handicrafts as one of its chief regulators, should provide support to the SME sector in the form of policies that facilitate an environment which is conducive to economic growth. Commercial banks must be encouraged to provide financial assistance to SMEs, even if doing so necessitates the government assuming responsibility for loans which are made to SMEs which have been assessed as being viable. 


\section{Limitations of the Study and Future Research Directions}

One of the principal limitations concerned the researcher being obliged to rely upon the subjective assessments of the respondents to the survey questionnaire and interviewees on the influence of Mobile Money on their turnover. The accuracy of the findings would improve significantly if the researcher had access to informal financial records and could observe the levels of turnover from the numbers of sales which were transacted before and after the adoption of Mobile Money in a longitudinal study. Also, it needs to be conceded that reducing the initial sample size of 384, which had been calculated through the formula of Cochran [59], to 285 could have altered the findings. Using growth for turnover as the sole determinant of the increased financial performance of the SMEs without investigating the influence of other factors could have constituted another limitation. The statistical analysis of the data did not include a normality test, and only significant variables were used in the inferential analysis. The degree to which the findings could be generalised to other target populations could also be limited unless the business practices of the SMEs concerned are very similar to those in the two markets in Douala.

To enhance the generalisability and credibility of the findings, further investigations on the topic in Cameroon should prioritise the use of quantitative methodologies. Additionally, for future research, turnover should be based upon recorded sales, even if the methods which are used to record sales are informal. Given that the paper relied on the use of cross-sectional data, further studies should benefit from the longitudinal survey. Finally, as the independent variables which were identified as contributing to variance in sales turnover were found to predict of the order of $73 \%$ of the variance, those which could predict the remaining $27 \%$ could be investigated in future studies.

Author Contributions: F.S.G.T. and R.K.T. designed and performed the study. All authors have read and agreed to the published version of the manuscript.

Funding: This research received no external funding.

Conflicts of Interest: The authors declare no conflict of interest.

\section{Appendix A}

Table A1. Reliability scores for each variable.

\begin{tabular}{cc}
\hline Variables & Cronbach's Alpha Score \\
\hline Use of Mobile Money services influences turnover & 0.609 \\
Use of MMS has increased turnover & 0.596 \\
Use of MMS has improved cash flow & 0.603 \\
Use of MMS has reduced the cost of transactions & 0.639 \\
Use of MMS has reduced transport costs & 0.659 \\
Use of MMS has reduced opportunity costs & 0.659 \\
MMS are more cost effective than those of traditional banks & 0.668 \\
MM service providers are reliable & 0.614 \\
MM transactions are safe & 0.626 \\
\hline
\end{tabular}

Source: authors.

\section{References}

1. OECD. Enhancing the Contributions of SMEs in a Global and Digitalised Economy; OECD: Paris, France, 2017; pp. 1-21.

2. Fiseha, G.G.; Oyelana, A.A. An assessment of the roles of small and medium enterprises (SMEs) in the local economic development (LED) in South Africa. J. Econ. 2015, 6, 280-290. [CrossRef]

3. National Institute of Statistics. Recensement General des Entreprises 2016; National Institute of Statistics: Yaoundé, Cameroon, 2018. Available online: http://slmp-550-104.slc.westdc.net/ \{\}stat54/downloads/2018/Pr ojet_de_rapport_preliminaire_RGE2_du_29_decembre_2017_final.pdf (accessed on 4 December 2019). 
4. Le Gicam. Accompagnement: Les PME au Coeur de la Stratégie du GICAM; Le Gicam: Douala, Cameroon, 2018; Available online: https:/www.legicam.cm/index.php/p/les-pme-au-coeur-de-la-strategie-du-gicam (accessed on 6 January 2019).

5. Ministry of Small and Medium Sized-Enterprises, Social Economy and Handicrafts. Annuaire Statistique des PMEESA 2018; Ministry of Small and Medium Sized-Enterprises, Social Economy and Handicrafts: Yaoundé, Cameroon, 2018. Available online: http://www.minpmeesa.gov.cm/site/inhoud/uploads/2019/05/ ANN-STAT-PMEESA-2018.pdf (accessed on 5 December 2019).

6. CCIMA. Un apercu synthetisé de l'actualité economique. In La Semaine Economique en Bref (51-11); CCIMA: Douala, Cameroon, 2015; pp. 1-2.

7. Gual, E. The Critical Issue of Cash Flow for SMEs. Available online: https://blog.strands.com/cashflow-andsmes (accessed on 5 December 2019).

8. Keizers, B.W.G. Determinants of Cash Holdings for Dutch SME's; University of Twente, The Faculty of Behavioural, Management and Social Sciences: Enschede, The Netherlands, 2017.

9. Oluoch, J.J. The impact of cash management practices on performance of SMEs: A survey of SMEs in Eldoret Central Business District. Iosr J. Econ. Financ. 2016, 7, 1-7.

10. Ngaruiya, B.; Bosire, M.; Kamau, S.M. Effect of Mobile Money transactions on the financial performance of small and medium enterprises in Nakuru central business district. Res. J. Financ. Account. 2014, 5, 53-58.

11. Mararo, M.W.; Ngahu, S. Influence of Mobile Money Services on the growth of SME in Nakuru town, Kenya. Iosr J. Hum. Soc. Sci. 2017, 22, 64-72.

12. European Commission. Diversity within Small and Medium-Sized Enterprises; European Commission: Luxembourg, 2015.

13. Peres, P.; Mesquita, A. Proceedings of the 2nd European Conference on Social Media 2015; Academic Conferences and Publishing International Limited: Porto, Portugal, 2015.

14. Muiruri, S.M. African small and medium enterprises (SMEs): Contributions, challenges and solutions. Eur. J. Res. Reflect. Manag. Sci. 2017, 5, 36-48.

15. Choto, P.; Tengeh, R.K.; Iwu, C.G. Daring to survive or to grow? The growth aspirations and challenges of survivalist entrepreneurs in South Africa. Environ. Econ. 2014, 5, 93-101.

16. Comninos, A.; Esselaar, S.; Ndiwalana, A.; Stork, C. M-Banking the unbanked. Res. ICT Afr. 2008, 1, 1-15.

17. Shukla, A.; Tyagi, R.; Raddi, S. Mobile payment 2.0: The next-generation model. In HSBC's Guide to Cash Supply Chain and Treasury Management in Asia Pacific; David Tait: Cyberport, Hong Kong, 2009; pp. 178-183.

18. Masocha, R.; Dzomonda, O. Adoption of Mobile Money Services and the performance of small and medium enterprises in Zimbabwe. Acad. Account. Financ. Stud. J. 2018, 22, 1-11.

19. Ngange, K.L.; Beng, P. Use of mobile phones for economic development in Cameroon. Adv. J. Commun. 2017, 5, 145-161. [CrossRef]

20. Investir au Cameroun. Le Secteur Bancaire Explique Pourquoi les PME Camerounaises Ont du Mal à Trouver des Financements; Investir au Cameroun: Yaoundé, Cameroon, 2018; Available online: https://www.investiraucameroun.com/economie/0207-11045-le-secteur-bancaire-explique-pourqu oi-les-pme-camerounaises-ont-du-mal-a-trouver-des-financements (accessed on 26 December 2018).

21. Amponsah, E.O. The advantages and disadvantages of Mobile Money on the profitability of the Ghanaian banking industry. Texila Int. J. Manag. 2018, 4, 1-8.

22. FINMARK Trust. Cameroon Pocket Guide; FINMARK Trust: Johannesburg, South Africa, 2017.

23. Higgins, D.; Kendall, J.; Lyon, B. Mobile Money usage patterns of Kenyan small and medium enterprises. Innovations 2012, 7, 67-81. [CrossRef]

24. Must, B.; Ludewig, K. Mobile Money: Cell phone banking in developing countries. Policy Matters J. 2010, 7, 27-33.

25. Mbogo, M. The impact of mobile payments on the success and growth of micro-business: The case of M-Pesa in Kenya. J. Lang Technol. Entrep. Afr. 2010, 2, 182-203. [CrossRef]

26. Ojong, N. Remittances, mobile phones and informality: Insights from Cameroon. Afr. J. Sci. Technol. Innov. Dev. 2016, 8, 299-308. [CrossRef]

27. Mwafise, A.M.; Stapleton, L. Determinants of user adoption of mobile electronic payment systems for microfinance institutions in developing countries: Case study Cameroon. Ifac Proc. Vol. 2012, 45, 38-43. [CrossRef] 
28. Shrier, D.; Canale, G.; Pentland, A. Mobile Money E Payments: Technology Trends; Massachusetts Institute of Technology, Connection Science \& Engineering: Cambridge, MA, USA, 2016.

29. European Investment Bank. Le Secteur Bancaire en Afrique Subsaharienne: Evolutions Récentes et Inclusion Financière Numérique; European Investment Bank: Luxembourg, 2016.

30. BEAC. Etat des Systemes de Paiement par Monnaie Electronique Dans la CEMAC. Available online: https: //docplayer.fr/88945930-Etat-des-systemes-de-paiement-par-monnaie-electronique-dans-la-cemac.html (accessed on 28 December 2018).

31. Chimaobi, O.V.; Chizoba, O. Boosting small and medium enterprises performance in Nigeria through mobile commerce. Eur. J. Bus. Manag. 2014, 6, 134-141.

32. Chale, P.R.; Mbamba, U. The role of Mobile Money Services on growth of SMEs in Tanzania: Evidence from Kinondoni district in DAR ES SALAAM region. Bus. Manag. Rev. 2014, 17, 81-96.

33. Nyaga, K.M.; Okonga, B.M. Does Mobile Money Services have any impact on SMEs performance in Naivasha? Int. J. Curr. Res. 2014, 6, 9394-9398.

34. MTN Cameroon. MTN MoMo. Available online: https://www.mtn.cm/en/mtn-mobile-money/ (accessed on 31 December 2018).

35. Orange Cameroon. Orange Money. Available online: https://www.orange.cm/en (accessed on 31 December 2018).

36. Business in Cameroon. In Cameroon, MTN and Orange Wage a Fierce Commercial War on the Mobile Money Market. Available online: https://www.businessincameroon.com/telecom/0202-6860-in-cameroon-mtn-andorange-wage-a-fierce-commercial-war-on-the-mobile-money-market (accessed on 2 February 2017).

37. The World Bank. Population Growth (Annual \%)-Cameroon. Available online: https://data.worldbank.org /indicator/SP.POP.GROW?end=2017\&locations=CM\&start=1995 (accessed on 7 December 2019).

38. The Economist. Mobile Money in Developing Countries. Available online: https:/www.economist.com/economicand-financial-indicators/2014/09/20/mobile-money-in-developing-countries (accessed on 29 December 2018).

39. Rubini, A. Fintech in a Flash; Createspace: London, UK, 2017.

40. Loi No 2010/001 du 13 Avril 2010 Portant Promotion des Petites et Moyennes Entreprises au Cameroun. 2010. Available online: https://www.izf.net/sites/default/files/loipme2015.pdf (accessed on 19 December 2019).

41. Afriland First Bank. (23 March 2015). Le Defis du Financement des pme-IMF. Available online: https: //www.imf.org/external/french/np/seminars/2015/brazzaville/pdf/AfrilandFR.pdf (accessed on 3 January 2019).

42. International Monetary Fund. Central African Economic and Monetary Community: Financial System Stability Assessment; International Monetary Fund: Washington, DC, USA, 2016.

43. Njabu, I.T. The impact of the Mobile Money Services on the Growth of Micro, Small and Medium Enterprises in Nkasi District Council. Master's Thesis, Mzumbe University, Nkasi, Tanzania, 2016. Available online: http://scholar.mzumbe.ac.tz/bitstream/handle/11192/1999/MSc_\%20Economics_Israel\%20Njabu\%20T 2016.pdf?sequence=1 (accessed on 26 December 2018). Unpublished.

44. Ministry of Small and Medium Enterprises, Social Economy and Handicrafts. Banque des PME. Available online: http://www.minpmeesa.gov.cm/site/pme/banque-des-pme/ (accessed on 3 January 2019).

45. Pinem, D.; Dwi, B. The analysis of company performance and sales growth to the dividend policy at the company Go Public in Indonesia stock exchange. Int. J. Bus. Commer. 2016, 5, 105-116.

46. Barbera, F.; Hasso, T. Do we need to use an accountant? The sales growth and survival benefits to family SMEs. Fam. Bus. Rev. 2013, 26, 271-292. [CrossRef]

47. John, E.K.; Gwahula, R.; Msemwa, F.M. The influence of perceived risk on the uptake of Mobile Money Services by SMEs operations in Karagwe district, Tanzania. Int. J. Adv. Eng. Manag. Sci. 2018, 4, 703-712. [CrossRef]

48. Baganzi, R.; Lau, A.K.W. Examining trust and risk in Mobile Money acceptance in Uganda. Sustainability 2017, 9, 2233. [CrossRef]

49. GSMA. Enabling Rural Coverage; GSMA: London, UK, 2018.

50. African Development Bank Group. Country Results Brief 2017 Cameroon; African Development Bank Group: Abidjan, Ivory Coast, Côte d'Ivoire, 2017.

51. Financial Inclusion. Pakistan Wave 4 Report FII Tracker Survey; InterMedia: Washington, DC, USA, 2017.

52. Business in Cameroon. Mobile Money Ready for Take-off in Cameroon; Mediamania Sarl: Genevia, Switzerland, 2015; Available online: http://www.businessincameroon.com/pdf/BC28.pdf (accessed on 23 January 2018). 
53. Business in Cameroon. Cameroon: Mobile Money Transactions Surged to FCFA 3500 Billion in 2017. Available online: https://www.businessincameroon.com/finance/3108-8300-cameroon-mobile-money-transactionssurged-to-cfa3-500bn-in-2017 (accessed on 31 August 2018).

54. Media Intelligence. Assessing the Active Use of Mobile Money Services in Cameroon; Media Intelligence: Yaoundé, Cameroon, 2016.

55. Polit, D.F.; Beck, C.T. Nursing Research: Principles and Methods, 7th ed.; Lippincott Williams \& Wilkins: Philadelphia, PA, USA, 2003.

56. Tengeh, R.K. A Business Framework for the Effective Start-Up and Operation of African Immigrant-Owned Businesses in the Cape Town Metropolitan Area, South Africa. Ph.D. Thesis, Cape Peninsula University of Technology, Cape Town, South Africa.

57. Fox, N.; Hunn, A.; Mathers, N. Sampling and sample size calculation. NIHR RDS East Midl.Yorks. Humber 2007, 1, 1-41.

58. Dudovskiy, J. The Ultimate Guide to Writing a Dissertation in Business Studies: A Step-by-Step Assistance. 2018. Available online: http://research-methodology.net/about-us/ebook/ (accessed on 19 December 2019).

59. Cochran, W.G. Sampling Techniques, 2nd ed.; John Wiley and Sons: New York, NY, USA, 1963.

60. Israel, G.D. Determining Sample Size; IFAS Extention: Gainesville, FL, USA, 2003; pp. 1-5.

61. Asoba, S.N. Factors influencing the Growth of African Immigrant-Owned Business in Selected Craft Markets in the Cape Metropolitan Area of South Africa. Master's Thesis, Cape Peninsula University of Technology, Cape Town, South Africa, 2014. Unpublished.

62. Creswell, J.W. Research Design: Qualitative, Quantitative and Mixed Methods Approaches, 4th ed.; Sage Publications: Los Angeles, CA, USA, 2014.

63. Goforth, C. University of Virginia Library. 16 November 2015. Available online: https://data.library.virginia. edu/using-and-interpreting-cronbachs-alpha/ (accessed on 19 May 2019).

64. Saunders, M.N.; Lewis, P.; Thornhill, A. Research Methods for Business Students; Pearson Education Limited: Harlow, UK, 2012.

(C) 2019 by the authors. Licensee MDPI, Basel, Switzerland. This article is an open access article distributed under the terms and conditions of the Creative Commons Attribution (CC BY) license (http://creativecommons.org/licenses/by/4.0/). 